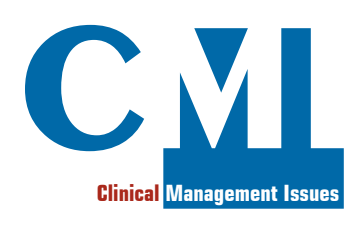

\title{
Cerebral Embolism Beyond Atrial Fibrillation: Interatrial Block
}

\begin{abstract}
This paper is devoted to conditions that imply a risk for cerebral embolism beyond atrial fibrillation (AF). We focus on advanced interatrial block (LAB) and its relationship with stroke in elderly patients with no documented arrhythmias. Advanced LAB is manifested in the surface electrocardiogram (ECG) as a P-wave duration $>120$ ms plus biphasic morphology (positive and negative deflection) in leads II, III, and aVF. Several data suggest that AF is not necessarily the leading cause of stroke, but rather a risk factor. In fact, a high stroke risk has been described even in the absence of AF in patients with high $\mathrm{CHA}_{2} \mathrm{DS}_{2} \mathrm{VASc}$-score (Congestive Heart failure, hypertension, Age $\geq 75$ years [doubled], Diabetes, Stroke [doubled], Vascular disease, Age 65-74 years, Sex category [female sex]). Moreover, excessive atrial ectopy and short atrial runs also increase stroke risk. Some of the previously mentioned stroke risk factors in patients without documented arrhythmias might be combined to determine thrombotic risk. That risk is particularly high in elderly patients with advanced IAB, structural heart disease, $C H A_{2} D S_{2}-V A S c$ score $\geq 3$, and frequent ambient atrial arrhythmias. Systematic screening for advanced LAB in elderly patients can be performed with a simple surface ECG. Advanced LAB is a risk marker of stroke.
\end{abstract}

Keywords: Stroke; Anticoagulation; Atrial Fibrillation; Risk Factor; ECG; Interatrial Block CMI 2020; 14(1): 51-59

bttp://dx.doi.org/10.7175/cmi.v14i1.1462

\section{INTRODUCTION}

Interatrial block $(\mathrm{IAB})$ is a cardiac rhythm dysfunction first described in 1941 [1] that leads to abnormal activation of left atrium [2], atrial fibrosis, atrial fibrillation (AF), and stroke. In this review, we focus on advanced $\mathrm{IAB}$ as a significant cause of stroke, regardless of the presence of AF. Several data suggest that AF is not necessarily the leading cause of stroke but rather a risk factor. In fact, a high stroke risk has been described in patients with high $\mathrm{CHA}_{2} \mathrm{DS}_{2} \mathrm{VASc}$-score (Congestive Heart failure, hypertension, Age $\geq 75$ years [doubled], Diabetes, Stroke [doubled], Vascular disease, Age 65-74 years, Sex category [female sex]) irrespective of the presence of AF [3,4].

The scope of this review paper is to describe advanced IAB as a risk marker of ischemic stroke. The study and knowledge of advanced IAB and its clinical consequences should be compulsory among physicians dealing with cardiovascular prevention, and systematic screening for advanced $I A B$ in elderly patients can be done with a simple surface electrocardiogram (ECG). Advanced IAB is a risk marker of stroke and has many similarities with AF [5,6].

\section{ISSUE DESCRIPTION: DEFINITION, MECHANISM, CLASSIFICATION AND DIAGNOSIS}

IAB is a cardiac rhythm disorder that represents a delay of conduction between right and left atria [7]. In healthy subjects, left atrial activation occurs mainly antero-
${ }^{1}$ Universidad Complutense de Madrid, Spain 2 Servicio de Cardiología, Hospital Universitario Central de Asturias, Oviedo, Spain ${ }^{3}$ Servicio de Cardiología, Hospital General Universitario Gregorio Marañón, Universidad Europea y Universidad Complutense, CIBERCV, Madrid, Spain
Corresponding author Manuel Martinez-Sellés, Servicio de Cardiología, Hospital General Universitario Gregorio Marañón,

Calle Doctor Esquerdo, 46, 28007 - Madrid, Spain mmselles@secardiologia.es

Received: 5 March 2020 Accepted: 10 September 2020 Published: 8 October 2020 
A

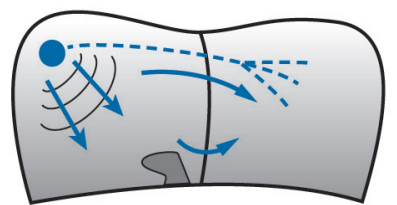

Normal
B

Slow conduction in Bachmann's bundle

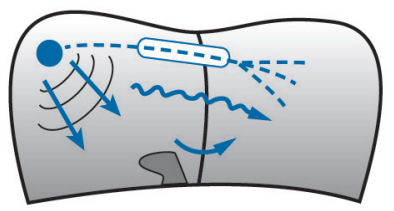

Partial IAB
C

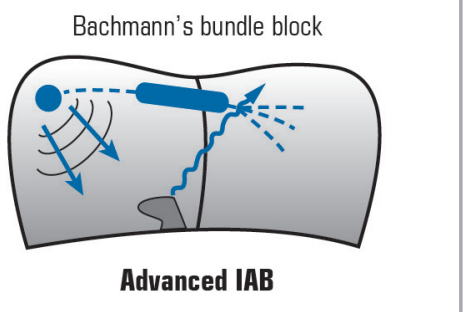

Figure 1. Atrial

activation in: A: healthy subjects; $B$ : with partial interatrial block (IAB); C: with advanced $I A B$.
Figure 2. Examples of normal P-wave, partial interatrial block (IAB), and advanced IAB. Adapted with permission from Martinez-Sellés et al. [15]. superior via Bachmann region. Impaired conduction in that region is generally the electrophysiological substrate for IAB. It has been classified in partial IAB ( $\mathrm{P}$-wave of 120 milliseconds or more) and advanced IAB ( $\mathrm{P}$-wave of 120 milliseconds or more and biphasic [positive and negative deflection] morphology in II, III, and aVF). Advanced $\mathrm{IAB}$ refers to complete conduction block at Bachmann region with the subsequent shifting of left atrial activation to posteroinferior connections with a retrograde caudocranial activation [8].

Atrial activation in healthy subjects and those with partial and advanced IAB is represented in Figure 1.

These concepts have been accepted in a consensus paper [8] and their characteristics follow:
- partial IAB (first-degree IAB):

- P-wave of 120 milliseconds or more is usually positive bimodal ( $\mathrm{P}$-wave is made up of two components, both positive), especially visible in leads I, II, or III. P-wave morphology in V1 is often negative (the vector moves away from the surface electrode, which results in a negative deflection);

- the P-wave has a normal electrical axis;

- left atrial enlargement is common [9]. The wide and bimodal $\mathrm{P}$-wave usually described in surface electrocardiogram (ECG) when there is left atrial enlargement is due to IAB rather than atrial enlargement;

- it has been related to AF and global and cardiovascular mortality [10];

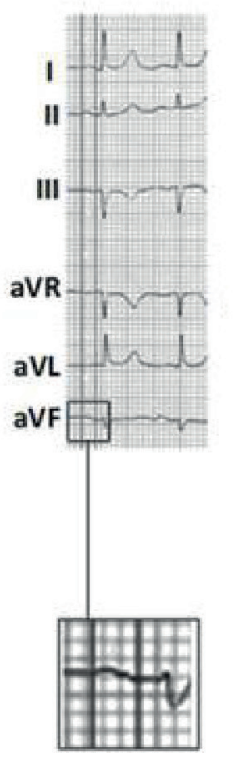

Normal P-wave

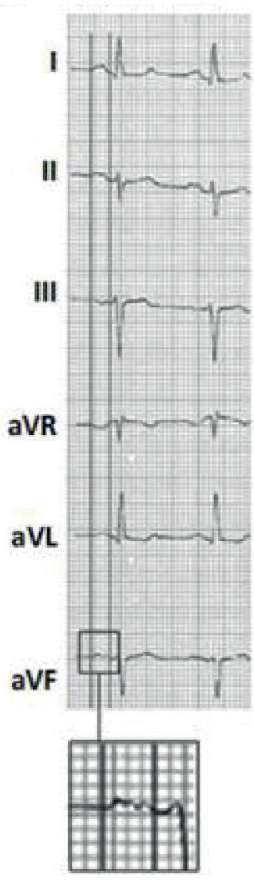

Partial IAB

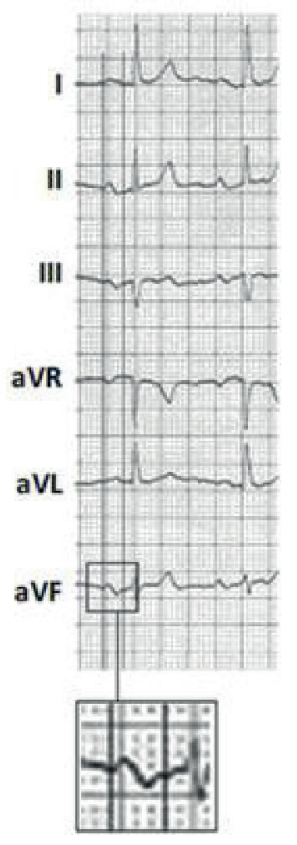

Advanced IAB 
- advanced IAB (third-degree IAB):

- P-wave duration of 120 milliseconds or more, usually positive in I and aVL, biphasic (positive and negative deflection) in II, III, and aVF and often in V1-V2;

- it is a very specific (90\%) [11] but insensitive marker of left atrial enlargement;

- it is associated with supraventricular arrythmias, especially in patients with structural heart disease [12];

- second-degree IAB [13]:

- it may occur transiently;

- P-wave morphology is changing (normal to IAB pattern; partial to advanced).

However, some advanced IAB do not perfectly comply with all the diagnosis criteria and is defined as atypical advanced IAB [14]. It can be atypical due to changes in $\mathrm{P}$-wave morphology or due to changes in $\mathrm{P}$-wave duration:

- atypical advanced IAB due to changes in P-wave morphology;

- type I: the terminal component of the $\mathrm{P}$-wave ( $\mathrm{P}$-wave is made up of two components) in lead II is flat rather than negative. Biphasic (positive and negative deflection) morphology in III and aVF;

- type II: the terminal component of the $\mathrm{P}$-wave in II is biphasic (positive and negative deflection);

- type III: the first component of the Pwave is flat in III and aVF;

- atypical advanced IAB due to changes in P-wave duration: $\mathrm{P}$-wave $<120$ ms biphasic (positive and negative deflection) in II, III, and aVF.

\section{DIAGNOSIS}

The clinical diagnosis is based on the surface ECG (Figure 2).

It is necessary to take into account that:

1. the ECG pattern may appear transiently and may change to more advanced forms;

2. the ECG pattern may appear without structural heart disease, although it may coexist;

3. the ECG pattern can be reproduced experimentally.

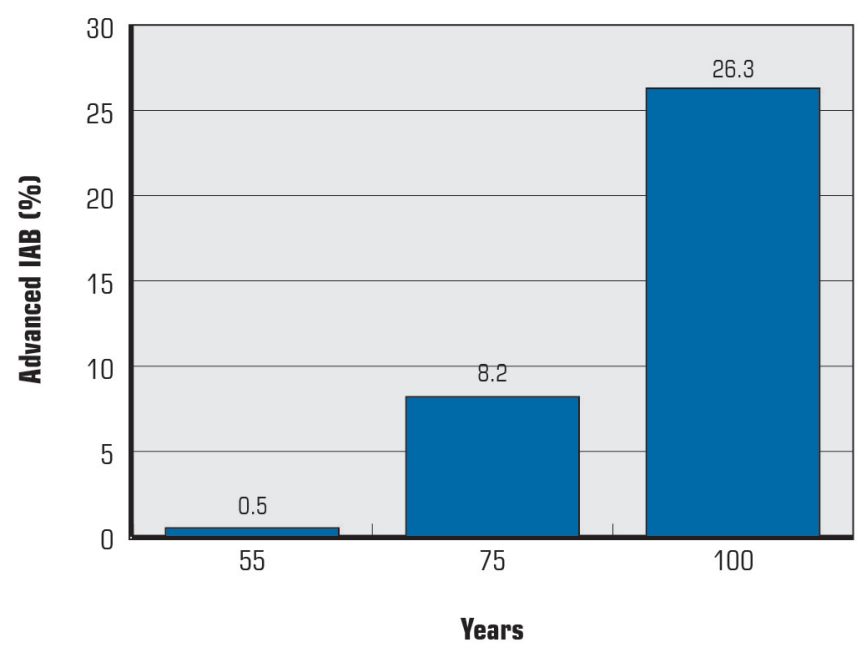

To perform a good measurement of the $\mathrm{P}$-wave duration, it is important to define the interval between the earliest detection of the $\mathrm{P}$-wave in any lead of the frontal plane and the lead were the end of the P-wave is detected. Other methods to detect the presence of IAB are the vectocardiogram, and invasive/noninvasive electro-mapping techniques $[16,17]$.

\section{EPIDEMIOLOGY: IAB AND AGE}

The prevalence of advanced and partial $\mathrm{IAB}$ is $1 \%$ and $9.7 \%$ respectively in the general population, and they are both associated with increased risk of AF [18]. Its prevalence increases with age, reaching a prevalence of $26 \%$ (advanced IAB) and $20.1 \%$ (partial IAB) in subjects aged $\geq 100$ years [15]. In the Atherosclerosis Risk in Communities (ARIC) study, only $0.5 \%$ of patients had advanced IAB at baseline (mean age 54 years \pm 5.8 ), but $1.6 \%$ developed advanced IAB during the mean 6-year follow-up. Incidence for advanced IAB was of 2.3 per 1000 persons-year [19]. Ageing is associated with a progressive increase in the degree of atrial fibrosis and modification in the cardiac conduction system, which led to IAB. AF, atrial premature beats and runs of atrial arrhythmias are also associated with age and with IAB [20]. Prevalence of advanced IAB in the general population according to age is shown in Figure 3.
Figure 3. Prevalence of advanced interatrial block (LAB) in the general population according to age. 


\section{PATHOPHYSIOLOGY, SUPRAVENTRICULAR ARRHYTHMIAS AND STROKE RISK}

The presence of advanced IAB indicates a delayed and abnormal left atrium activation with abnormal contraction against a closed mitral valve, thus increasing left atrial pressure, wall stress, and left atrium enlargement. Left atrial enlargement may contribute to left ventricular diastolic dysfunction and increase left ventricular filling pressures. Moreover, atrial remodelling leads to progressive atrial fibrosis [21,22], which also is associated with ageing, and contributes to atrial dysfunction. Atrial fibrosis and function have been studied with speckle tracking echocardiography, reporting a decrease in the absolute value of the strain rate during atrial booster pump function and early reservoir period [23]. In cardiac magnetic resonance, a late gadolinium enhancement of the upper part of the septum involving Bachmann's bundle has been reported, describing the association between IAB and atrial fibrosis [24]. This may result in endothelial dysfunction, with a hypercoagulable state comparable to that present in AF [25] and a stagnant and sluggish left atrium favoring the appearance of stasis-induced thrombosis, especially in the left atrial appendage, even in the absence of supraventricular arrhythmias.

Some studies suggest that patients with high $\mathrm{CHA}_{2} \mathrm{DS}_{2}$ VASc-score have a high stroke risk irrespective of the presence of $\mathrm{AF}$ $[3,4]$. Tischer et al. [3] found that, in patients with score $\mathrm{CHA}_{2} \mathrm{DS}_{2} \mathrm{VASc}$-score $>5$, the prevalence of stroke was high irrespective of AF. Other authors also suggested that the risk of stroke is high, even in the absence of documented arrhythmias, particularly in the presence of arrhythmic symptoms [4], previous myocardial infarction [26], or heart failure [27]. These data support the notion that $\mathrm{AF}$ is a risk factor for ischemic stroke, but not necessarily the direct cause of it. Furthermore, the causality of the association $\mathrm{AF}$-ischemic stroke is questioned by the reported lack of temporal relation between stroke events and AF paroxysms or atrial high-rate episodes detected by implantable loop recorders or devices [28-34].

Also, an association between advanced IAB and supraventricular arrhythmias and poor left atrium contractility has been reported. This is called Bayes' Syndrome [35]. This association may be explained by atrial fibrosis and left atrium enlargement. Also, this could be due to re-entry, as conduction disturbances increase refractory period dispersion. Finally, IAB is associated with premature atrial beats probably due to abnormal left atrium activation facilitating the initiation of re-entry and AF. Atrial ectopy is also a predictor of AF [36]. Excessive supraventricular ectopic activity (defined as the presence of either $\geq 30$ premature atrial contractions/hour daily or any runs of $\geq 20$ premature atrial contractions) is associated with an increased risk of ischemic stroke [25]. Even premature atrial contractions detected on the routine screening electrocardiogram are associated with an increased risk of ischemic stroke $[37,38]$.

\section{IAB IN SPECIFIC CARDIAC CONDITIONS}

\section{IAB and Tako-Tsubo Syndrome}

The prevalence of IAB in Tako-Tsubo syndrome is about $30 \%$ and has been independently associated with a poor prognosis. ECG from 246 patients included in the Spanish multicenter REgistry of TAKOtsubo syndrome (RETAKO) showed that $61 \%$ of them had normal P-wave, while $24 \%$ had partial IAB, $7 \% \mathrm{AF}$, and $5 \%$ advanced IAB. Patients with advanced IAB were older. The primary endpoint was a composite endpoint of all-cause mortality and hospital readmission and was significantly higher in patients with $\mathrm{AF}$ or advanced IAB (33\% and $31 \%$ respectively). Survival free from mortality, Tako-Tsubo syndrome recurrence, and hospitalization were significantly lower in patients with AF or advanced IAB $[39,40]$.

\section{IAB and Coronary Artery Disease}

In patients with acute ST-segment elevation myocardial infarction (STEMI), IAB was also associated with poor prognosis, but that was not an independent association, as the effect was mainly related to age [41]. In 972 consecutive patients with STEMI and sinus rhythm at discharge, $\mathrm{P}$-wave was normal in $72.8 \%, 21.3 \%$ had partial IAB, and $5,9 \%$ had advanced IAB. Patients with advanced IAB were older and had more hypertension. During a mean follow-up of $49.6 \pm 24.9$ months, $11.7 \%$ of patients died, $6.8 \%$ presented $\mathrm{AF}$, and $2.9 \%$ had a stroke. However, multivariable Cox analysis did not show an independent association be- 
tween IAB and prognosis. Although they found higher all-cause mortality, this was due to age.

The IFFANIAM study (Impacto de la Fragilidad y el estado Funcional en el Anciano con Infarto Agudo de Miocardio sometido a angioplastia primaria) is a Spanish multicenter registry conducted to assess the prognostic role of frailty and other ageing-related variables in patients with STEMI aged 75 years or older. 254 patients were included, $86.6 \%$ were in sinus rhythm. From them, 16.8\% had partial IAB and $15.5 \%$ advanced IAB. Patients with advanced IAB were older and the degree of IAB and the prevalence of hypertension, previous stroke and the number of different chronic treatments had a linear association. They did not observe significant differences regarding comorbidity, functional status, nutritional risk, and cognitive status according to interatrial conduction. They also found a trend to linear association between the degree of IAB and mortality [42].

IAB was related to coronary artery disease in a recent analysis of 322 patients. $31.7 \%$ and $6.5 \%$ of them had partial IAB and advanced $I A B$, respectively. The incidence of new-onset $\mathrm{AF}$ was $10.6 \%$ [43].

\section{IAB and Heart Failure}

The prospective observational "Bayes' Syndrome-HF” study included 1050 patients with heart failure. 464 patients in sinus rhythm and with a measurable $\mathrm{P}$-wave were analyzed. $20.5 \%$ and $23.5 \%$ of them had partial and advanced IAB, respectively. Advanced IAB was independently associated with new-onset AF (HR 2.71 CI [1.614.56], $\mathrm{P}<0.001$ ), ischemic stroke (HR 3.02 [1.07-8.53], $\mathrm{P}=0.04)$, and a composite of both (HR 2.42 [1.41-4.15], P 0 0.001) [44].

\section{IAB and Transcatheter Aortic Valve Implant (TAVI)}

Aortic stenosis is the most frequent valve disease in the elderly and TAVI is becoming the standard therapy in symptomatic patients. One of the main side effects are conduction disturbances. No study has analyzed the association and the requirement of a permanent pacemaker in this context. The Baseline Interatrial block and Transcatheter aortic valve implantation (BIT) registry will study the influence of previous IAB on the need for permanent pacemaker after TAVI [45].

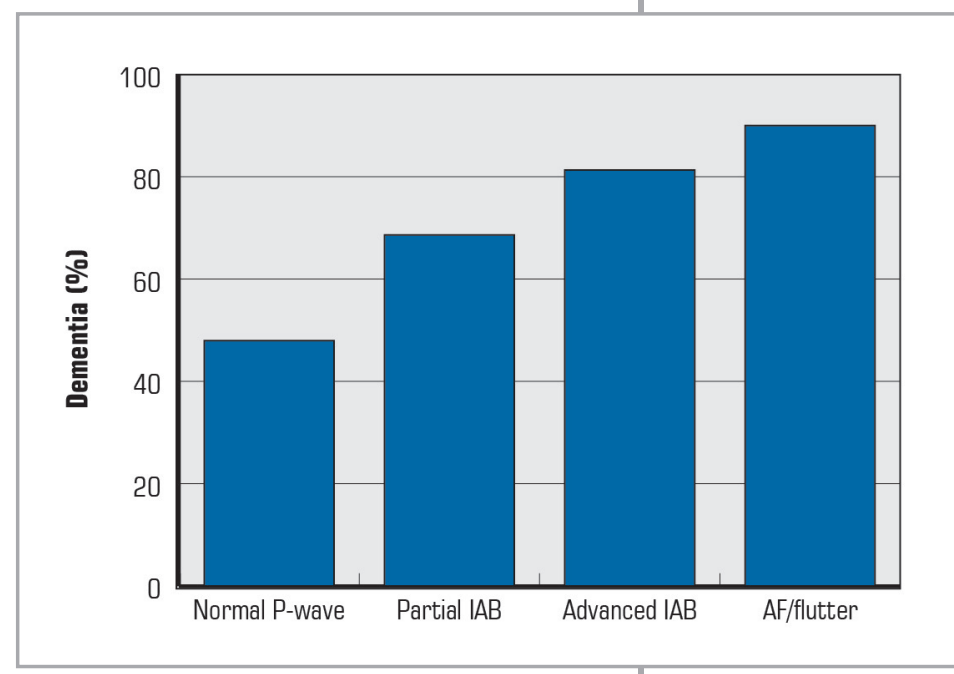

\section{IAB and Dementia}

The association of AF with mild cognitive impairment and dementia is already unquestionable [46]. The pathophysiological mechanisms that justify this association have not been fully clarified, but they are probably multifactorial. These mechanisms include the most obvious, such as symptomatic ischemic stroke and silent cerebral infarcts/micro-infarcts [47], to cerebral hemorrhages and cerebral hypoperfusion due to hemodynamic alterations. In fact, reductions in cardiac output and decreases in diastolic cerebral arterial flow might play a role [48]. In the case of advanced IAB, the association seems to be very similar. In the study Scientific Characterization of the Centennial Heart-Caracterización Cientifica del Corazón del Centenario (4C) [18], the prevalence of dementia increased progressively from normal $\mathrm{P}$-wave, partial IAB, advanced $\mathrm{IAB}$, and AF (Figure 4).

This independent association is probably mainly due to silent cerebral infarctions, although other factors such as chronic cerebral hypoperfusion may also play a role. This advanced IAB-dementia relationship suggests the need for systematic cognitive screening in patients with advanced IAB. Besides, the presence of advanced IAB should also be ruled out in patients with cognitive dysfunction.

\section{TREATMENT}

Patients with advanced IAB and previous episodes of documented AF (Bayés syndrome) should be treated like other patients with a history of AF. In terms of strategy,
Figure 4. Prevalence of dementia in the registry Scientific Characterization of the Centennial Heart (4C) based on the presence and type of interatrial block (LAB) and atrial fibrillation $(A F)$ /atrial flutter (flutter). 
the presence of advanced IAB is an independent predictor of recurrence of $\mathrm{AF}$, which in some cases can tip the balance towards frequency control.

Patients with advanced IAB without previous episodes of documented $\mathrm{AF}$ also have an increased risk of stroke, particularly in the presence of other risk factors such as advanced age, diabetes, hypertension, and structural heart disease. However, at this time, we do not have clinical trials that support the use of anticoagulants in the absence of documented AF. Therefore, it is crucial to carry out monitoring to look for AF episodes that can support anticoagulation in these patients $[49,50]$. We suggest ECG in every consultation and 24-hour ECG monitoring to detect $\mathrm{AF}$ episodes. We believe that it would be desirable to carry out a randomized study, with one arm of a direct-acting oral anticoagulant and another with a placebo, in patients with advanced IAB who also have other previously mentioned risk factors [51-53].

\section{FUTURE PERSPECTIVES}

The BAYES registry [6] is a prospective, multicentre, international, and observational registry that has been conducted at 35 centres with 3-year follow-up. Patients 70 years or older with structural heart disease and sinus rhythm were involved. The registry included 3 similar-size groups of patients: patients with normal $\mathrm{P}$-wave, patients with partial IAB, and patients with advanced
IAB. Clinical follow-up was carried out by local investigators and visits were planned at $6,12,18,24$, and 36 months. The primary endpoints were: an $\mathrm{AF}$ episode longer than 5 minutes and documented in any ECG recording and ischemic stroke. Other secondary endpoints as the initiation of anticoagulation, cognitive impairment, and all-cause mortality were reported. This registry results are about to be published and will contribute to assessing the influence of these 3 factors, opening the door to perform, for the first time, a clinical trial comparing anticoagulation with placebo, to try to change the present paradigm that makes AF necessary to prescribe anticoagulation to these patients.

A better knowledge of IAB, a separate entity from left atrial enlargement [54] that is associated with $\mathrm{AF}$ and stroke $[55,56]$, is essential to clarify the correct future approach in these patients. Also, the influence of other $\mathrm{P}$-wave indexes in the prognosis should be taken into consideration in the decisionmaking process.

\section{CONCLUSION}

Even in the absence of documented arrhythmias, the risk of stroke is high in elderly patients with advanced IAB, particularly if they also have high $\mathrm{CHA}_{2} \mathrm{DS}_{2} \mathrm{VASc}$-score and excessive atrial ectopy. These 3 variables should be included in the assessment of stroke risk in advanced-age patients. Future clinical trials will help elucidate whether anticoagulation is needed in these patients.

Key Points

- The risk of stroke is high in elderly patients with advanced $I A B$

- $C H A_{2} D S_{2}-V A S c$-score should be assessed in these patients, although AF is not present

- Screening for supraventricular arrhythmias should also be considered

- IAB, CHA $\mathrm{DS}_{2}$-VASc-score, and supraventricular arrhythmias should be included in the assessment of stroke risk in elderly

- It is essential to assess future studies if anticoagulation is needed

\section{Funding}

This article has been published without the support of sponsors.

\section{Conflicts of interests}

The authors declare they have no competing financial interests concerning the topics of this article. 


\section{REFERENCES}

1. Bachmann G. The significance of splitting of the P-wave in the ECG. Ann Intern Med 1941; 14: 1702-9; https://doi.org/10.7326/0003-4819-14-9-1702

2. Goyal S, Spodick D. Electromechanical dysfunction of the left atrium associated with interatrial block. Am Heart J 2001; 142: 823-7; https://doi.org/10.1067/mhj.2001.118110

3. TischerTs, Schneider R, Lauschke J, et al. Prevalence of atrial fibrillation in patients with high CHADS2- and CHA2DS2VASc-scores: anticoagulate or monitor high-risk patients? Pacing Clin Electrophysiol 2014; 37: 1651-7; https://doi.org/10.1111/pace.12470

4. Zuo ML, Liu S, Chan KH, et al. The CHADS2 and CHA 2DS 2-VASc scores predict new occurrence of atrial fibrillation and ischemic stroke. J Interv Card Electrophysiol 2013; 37: 4754; https://doi.org/10.1007/s10840-012-9776-0

5. Kirchhof P, Benussi S, Kotecha D, et al. 2016 ESC Guidelines for the management of atrial fibrillation developed in collaboration with EACTS. Eur Heart J 2016; 37: 2893-962; https:// doi.org/10.1093/eurheartj/ehw210

6. Martínez-Sellés M, Baranchuk A, Elosua R, et al. Rationale and design of the BAYES (Interatrial Block and Yearly Events) registry. Clin Cardiol 2017; 40: 196-9; https://doi. org/10.1002/clc.22647

7. Bayés de Luna A. Bloqueo a nivel auricular. Rev Esp Cardiol 1979; 32: 5-10.

8. Bayés de Luna A,Platonov P, Cosio FG, et al. Interatrial blocks. A separate entity from left atrial enlargement: a consensus report. J Electrocardiol 2012; 45: 445-51; https://doi.org/10.1016/j. jelectrocard.2012.06.029

9. Spodick DH, Ariyarajah V. Interatrial block: a prevalent, widely neglected and portentous abnormality. J Electrocardiol 2008; 41: 61; https://doi.org/10.1016/j.jelectrocard.2007.02.006

10. MagnaniJW, Gorodeski EZ, Johnson VM, et al. P wave duration is associated with cardiovascular and all-cause mortality outcomes: the National Health and Nutrition Examination Survey.Heart Rhythm 2011; 8: 93; https://doi.org/10.1016/j.hrthm.2010.09.020

11. Bayés de Luna A, Fort de Ribot R, Trilla E, et al.Electrocardiographic and vectorcardiographic study of interatrial conduction disturbances with left atrial retrograde activation. J Electrocardiol 1985; 18: 1; https://doi.org/10.1016/S0022-0736(85)80029-7

12. Bayés de Luna A, Guindo J, Viñolas X, et al.Third-degree inter-atrial block and supraventricular tachyarrhythmias. Europace 1999; 1: 43; https://doi.org/10.1053/eupc.1998.0006

13. Bayés de Luna A, Baranchuk A, Niño Pulido C, et al. Second-degree interatrial block: Brief review and concept.Ann Noninvasive Electrocardiol 2018; 23: e12583; https://doi.org/10.1111/ anec. 12583

14. Bayés de Luna A, Escobar-Robledo LA, Aristizabal D, et al. Atypical advanced interatrial blocks: Definition and electrocardiographic recognition. J Electrocardiol 2018; 51: 1091-3; https://doi. org/10.1016/j.jelectrocard.2018.09.004

15. Martínez-Sellés M, Massó-van Roessel A, Álvarez-García J, et al. Interatrial block and atrial arrhythmias in centenarians: Prevalence, associations, and clinical implications. Heart Rhythm 2016; 13: 645-51; https://doi.org/10.1016/j.hrthm.2015.10.034

16. Hernandez-Betancor I, Izquierdo-Gomez MM, Garcia-Niebla J,et al. Bayes Syndrome and imaging techniques. Curr Cardiol Rev 2017; 13: 263-73; https://doi.org/10.2174/157340 3X13666170713122600

17. Bayés de Luna A, Baranchuk A, Escobar Robledo LA, et al. Diagnosis of interatrial block. J Geriatr Cardiol 2017; 14: 161-5; https://doi.org/10.11909/j.issn.1671-5411.2017.03.007.

18. Istolahti T, Eranti A, Huhtala $\mathrm{H}$, et al. The prevalence and prognostic significance of interatrial block in the general population. Ann Med 2020; 20: 1-23; https://doi.org/10.1080/07853890 2020.1731759

19. O'Neal WT, Kamel H, Zhang ZM, et al. Advanced interatrial block and ischemic stroke: The Atherosclerosis Risk in Communities Study. Neurology 2016; 87:352-6; https://doi.org/10.1212/ WNL.0000000000002888

20. Martínez-Sellés M. Prevalence and incidence of interatrial block in global population and in different clinical situations. J Geriatr Cardiol 2017; 14: 158-60; https://doi.org/10.11909/j. issn.1671-5411.2017.03.006.

21. Goyal S, Spodick D. Electromechanical dysfunction of the left atrium associated with interatrial block. Am Heart J 2001; 142: 823-7; https://doi.org/10.1067/mhj.2001.118110

22. Johner N, Mehdi N, Shah DC. Intra- and interatrial conduction abnormalities: hemodynamic and arrythmic significance. J Interv Card Electrophysiol 2018; 52: 293-302; https://doi. org/10.1007/s10840-018-0413-4 
23. LaCalzada-Almeida J, Izquierdo-Gómez MM, Belleyo-Belkasem C, et al. Interatrial block and atrial remodeling assessed using speckle tracking echocardiography. BMC Cardiovasc Disord 2018; 18: 38; https://doi.org/10.1186/s12872-018-0776-6

24. Benito EM, De Luna AB, Baranchuk A, et al. Extensive atrial fibrosis assessed by late gadolinium enhancement cardiovascular magnetic resonance associated with advanced interatrial block electrocardiogram pattern. Europace 2017; 19: 377; https://doi.org/10.1093/europace/euw294

25. Larsen BS, Kumarathurai P, Falkenberg J. Excessive atrial ectopy and short atrial runs increase the risk of stroke beyond incident atrial fibrillation.J Am Coll Cardiol 2015; 66: 232-41; https:// doi.org/10.1016/j.jacc.2015.05.018

26. Lau KK, Chan PH, Yiu KH, et al. Roles of the CHADS2 and CHA2DS2-VASc scores in post-myocardial infarction patients: Risk of new occurrence of atrial fibrillation and ischemic stroke. Cardiol J 2014; 21: 474-83; https://doi.org/10.5603/CJ.a2014.0034

27. Melgaard L, Gorst-Rasmussen A, Lane DA, et al. Assessment of the CHA2DS2-VASc Score in Predicting Ischemic Stroke, Thromboembolism, and Death in Patients With Heart Failure With and Without Atrial Fibrillation. JAMA 2015; 314: 1030-8; https://doi.org/10.1001/ jama.2015.10725

28. James R, Atul V,Halperin JL, et al. Rationale and design of REVEAL AF: a prospective study of previously undiagnosed atrial fibrillation as documented by an insertable cardiac monitor in high-risk patients. Am Heart J 2014; 167: 22; https://doi.org/10.1016/j.ahj.2013.10.007

29. Gladstone D, Spring M, Dorian P, et al. (EMBRACE Investigators and Coordinators). Atrial fibrillation in patients with cryptogenic stroke. N Engl J Med 2014; 370: 2467-77; https://doi. org/10.1056/NEJMoa1311376

30. Sanna T, Diener HC, Passman R, et al. (CRYSTAL AF Investigators). Cryptogenic stroke and underlying atrial fibrillation. N Engl J Med 2014; 370: 2478-86; https://doi.org/10.1056/ NEJMoa1313600

31. Benezet-Mazuecos J, Rubio JM, Farré J. Atrial high rate episodes in patients with dual-chamber cardiac implantable electronic devices: unmasking silent atrial fibrillation. PACE 2014; 37: 1080-6; https://doi.org/10.1111/pace.12428

32. Glotzer TV, Daoud EG,Wyse DG, et al. The relationship between daily atrial tachyarrhythmia burden from implantable device diagnostics and stroke risk: the TRENDS study. Circ Arrhythm Electrophysiol 2009; 2: 474-80; https://doi.org/10.1161/CIRCEP.109.849638

33. Hohnoloser SH, Capucci A, Fain E, et al. ASSERT Investigators and Committees. Asymptomatic atrial fibrillation and stroke evaluation in pacemaker patients and the atrial fibrillation reduction atrial pacing Trial (ASSERT). Am Heart J 2006; 152: 442-7; https://doi. org/10.1016/j.ahj.2006.02.016

34. Martin DT, Bersohn MM, Waldo AL, et al. IMPACT Investigators. Randomized trial of atrial arrhythmia monitoring to guide anticoagulation in patients with implanted defibrillator and cardiac resynchronization devices. Eur Heart J 2015; 36: 1660-8; https://doi.org/10.1093/ eurheartj/ehv115

35. Bacharova L, Wagner GS. The time for naming the interatrial block Syndrome: Bayes Syndrome. J Electrocardiol 2015; 48: 133-4; https://doi.org/10.1016/j.jelectrocard.2014.12.022

36. Kumarathurai P, Mouridsen MR, Mattsson N, et al. Atrial ectopy and N-terminal pro-B-type natriuretic peptide as predictors of atrial fibrillation: a population-based cohort study. Europace 2017; 19: 364-70; https://doi.org/10.1093/europace/euw017

37. O'Neal WT, Kamel H, Kleindorfer D, et al. Premature Atrial Contractions on the Screening Electrocardiogram and Risk of Ischemic Stroke: The Reasons for Geographic and Racial Differences in Stroke Study. Neuroepidemiology 2016; 47: 53-8; https://doi. org/10.1159/000448619

38. Ofoma U,He F, Shaffer ML, et al. Premature cardiac contractions and risk of incident ischemic stroke.J Am Heart Assoc 2012; 1: e002519; https://doi.org/10.1161/JAHA.112.002519

39. García-Niebla J, Lacalzada-Almeida J, Díaz-Muñoz J, et al. Interatrial block and takotsubo syndrome. Europace 2019; 21: 1755; https://doi.org/10.1093/europace/euz241

40. Martín-Demiguel I, Núñez-Gil IJ, Pérez-Castellanos A, et al. Prevalence and Significance of Interatrial Block in Takotsubo Syndrome (from the RETAKO Registry). Am J Cardiol 2019; 123: 2039-43; https://doi.org/10.1016/j.amjcard.2019.03.028

41. Bruña V, Velásquez-Rodríguez J, Valero-Masa MJ, et al. Prognostic of interatrial block after an acute ST-segment elevation myocardial infarction. Cardiology 2019; 142: 109-15; https:// doi.org/10.1159/000499501

42. Bernal E, Bayés-Genís A, Ariza-Solé A, et al. Interatrial block, frailty and prognosis in elderly patients with myocardial infarction. J Electrocardiol 2018; 51: 1-7; https://doi.org/10.1016/j. jelectrocard.2017.08.026 
43. Alexander $\mathrm{B}, \mathrm{Haseeb} \mathrm{S}$, van Rooy $\mathrm{H}$, et al. Reduced $\mathrm{P}$-wave voltage in lead I is associated with development of atrial fibrillation in patients with coronary artery disease. J Atr Fibrillation 2017; 10: 1657; https://doi.org/10.4022/jafib.1657

44. Escobar-Robledo LA, Bayés-de-Luna A, Lupón J, et al. Advanced interatrial block predicts newonset atrial fibrillation and ischemic stroke in patients with heart failure: The "Bayes'SyndromeHF” study. Int J Cardiol 2018; 271: 174-80; https://doi.org/10.1016/j.ijcard.2018.05.050

45. Martínez-Sellés M, Escobar-Robledo LA, Bernal E, et al. Rational and design of the Baseline Interatrial block and Transcatheter aortic valve implantation (BIT) registry. $J$ Electrocardiol 2019; 57: 100-3; https://doi.org/10.1016/j.jelectrocard.2019.09.016

46. Diener HC, Hart RG, Koudstaal PJ, et al. Atrial fibrillation and cognitive function: JACC review topic of the week.J Am Coll Cardiol 2019; 73: 612-9; https://doi.org/10.1016/j.jacc.2018.10.077

47. Conen D, Rodondi N, Müller A, et al; Swiss-AF Study Investigators. Relationships of overt and silent brain lesions with cognitive function in patients with atrial fibrillation. $\mathrm{J} \mathrm{Am} \mathrm{Coll}$ Cardiol 2019; 73: 989-99; https://doi.org/10.1016/j.jacc.2018.12.039

48. Bunch TJ, Galenko O, Graves KG, et al. Atrial fibrillation and dementia: exploring the association, defining risks and improving outcomes. Arrhythm Electrophysiol Rev 2019; 8: 8-12; https://doi.org/10.15420/aer.2018.75.2

49. Bayés de Luna A, Martínez-Sellés M, Bayés-Genís A, et al. Surface ECG interatrial blockguided treatment for stroke prevention: rationale for an attractive hypothesis. BMC Cardiovasc Disord 2017; 17: 211; https://doi.org/10.1186/s12872-017-0650-y

50. Martínez-Sellés M, Fernández Lozano I, Baranchuk A, et al. Should we anticoagulate patients at high risk of atrial fibrillation? Rev Esp Cardiol 2016; 69: 374-6; https://doi.org/10.1016/j. rec.2016.01.008

51. Martínez-Sellés M, García-Izquierdo Jaén E, Fernández Lozano I. Anticoagulation in elderly patients at high risk of atrial fibrillation without documented arrhythmias. J Geriatr Cardiol 2017; 14: 166-8; https://doi.org/10.11909/j.issn.1671-5411.2017.03.004

52. Baranchuk A, Alexander B, Cinier G, et al. Bayés' syndrome: Time to consider early anticoagulation? North Clin Istanb 2018; 5: 370-8; https://doi.org/10.14744/nci.2017.60251

53. Bayés de Luna A, Martínez-Sellés M, Bayés-Genís A, et al. What every clinician should know about Bayés Syndrome. Rev Esp Cardiol 2020; 73: 758-62; https://doi.org/10.1016/j. rec.2020.04.026

54. Guerra JM, Vilahur G, Bayés de Luna A, et al. Interatrial block can occur in the absence of left atrial enlargement: New experimental model. PACE 2020; 43: 427-9; https://doi.org/10.1111/ pace. 13895

55. Bayés de Luna A, Martínez-Sellés M, Elosua R, et al. Relation of advanced interatrial block to risk of atrial fibrillation and stroke. Am J Cardiol 2020; 125: 1745-8; https://doi.org/10.1016/j. amjcard.2020.02.034

56. Alexander B, Milden J, Hazim B, et al. New electrocardiographic score for the prediction of atrial fibrillation: The MVP ECG risk score (morphology-voltage-P-wave duration). Ann Noninvasive Electrocardiol 2019; 24: e12669; https://doi.org/10.1111/anec.12669 